\title{
BMJ Open Impact of newly constructed primary healthcare centres on antenatal care attendance, facility delivery and all- cause mortality: quasi-experimental evidence from Taabo health and demographic surveillance system, Côte d'Ivoire
}

\author{
Siaka Koné (D) , ${ }^{1,2,3}$ Bassirou Bonfoh, ${ }^{1}$ Nicole Probst-Hensch, ${ }^{2,3}$ Jürg Utzinger, ${ }^{2,3}$ \\ Eliézer K N'Goran, ${ }^{1,4}$ Günther Fink ${ }^{2,3}$
}

To cite: Koné S, Bonfoh B, Probst-Hensch N, et al. Impact of newly constructed primary healthcare centres on antenatal care attendance, facility delivery and all-cause mortality: quasi-experimental evidence from Taabo health and demographic surveillance system, Côte d'Ivoire. BMJ Open 2022;12:e054355. doi:10.1136/ bmjopen-2021-054355

- Prepublication history and additional supplemental material for this paper are available online. To view these files, please visit the journal online (http://dx.doi.org/10.1136/ bmjopen-2021-054355).

Received 12 June 2021 Accepted 10 January 2022

(D) Check for updates

(c) Author(s) (or their employer(s)) 2022. Re-use permitted under CC BY-NC. No commercial re-use. See rights and permissions. Published by BMJ.

For numbered affiliations see end of article.

Correspondence to

Siaka Koné; siaka.kone@csrs.ci

\section{ABSTRACT}

Objectives Access to quality care remains limited, particularly in low-income and middle-income countries. Although better health outcomes for families living in close proximity to healthcare facilities have been documented in cross-sectional studies, evidence on the extent to which additional health facilities can contribute to improved population health remains scanty. We aimed to estimate the causal impact of newly constructed primary healthcare facilities within a health and demographic surveillance (HDSS) site in Côte d'Ivoire.

Design We conducted a quasi-experimental study. Logistic and Cox proportional hazards regression models were used to estimate the impact of new healthcare facilities on healthcare-seeking behaviour and all-cause mortality.

Setting Data were collected prospectively through the Taabo HDSS located in south-central Côte d'Ivoire between 2010 and 2018.

Participants We analysed 2957 deaths across 440973 person-year observations as well as 14132 live births. Primary outcome measures The primary outcomes were antenatal care (ANC) attendance, facility delivery and mortality. Logistic and Cox proportional hazards models were employed to estimate the impact of the new health facilities on ANC attendance, facility delivery and child as well as adult mortality.

Results Average distance to the nearest healthcare facility declined from $5.5 \mathrm{~km}$ before to $2.8 \mathrm{~km}$ after opening of four new healthcare facilities in targeted villages. No improvement was observed for ANC attendance, institutional deliveries and adult mortality. New facilities reduced the risk of post-neonatal infant mortality by $46 \%$ (HR $0.54,95 \% \mathrm{Cl} 0.31$ to $0.94, \mathrm{p}<0.05$ ), suggesting a mortality gradient of 2 deaths per 1000 for each additional $\mathrm{km}$ (Coef $=0.002,95 \% \mathrm{Cl} 0.000$ to 0.004 , $\mathrm{p}<0.05)$.

Conclusions Our results suggest that new facilities do not necessarily improve healthcare utilisation and health
Strengths and limitations of this study

- We used 9 years of longitudinal surveillance data from a well-characterised population-based cohort to estimate the impact of newly constructed health facilities on the utilisation of essential maternal health services as well as child and adult mortality.

- The health facilities evaluated are representative of a considerable number of primary healthcare centres built in recent years in Côte d'Ivoire and elsewhere in low-income and middle-income countries.

- Our results are based on a small number $(n=4)$ of newly constructed health facilities with only one staff member and limited diagnostic tools. Hence, observed impacts may be different in other settings.

- The relatively small number of child deaths in our sample limiting our statistical power for child mortality outcomes.

- Euclidean distance calculation from the household to the nearest health facility underestimates true distances and travel times on the ground.

outcomes. Further research is needed to identify the best ways to ensure access to quality care in resourceconstrained settings.

\section{BACKGROUND}

While substantial progress has been made in reducing under-5 mortality worldwide from 1990 to 2015 , the decline in child mortality has only been moderate in many parts of subSaharan African (SSA), making it increasingly challenging to reach the ambitious targets set within the Sustainable Development Goals agenda. ${ }^{1}$ As of 2015 , an estimated 2.9 million under-5 deaths were reported 
in SSA. ${ }^{2}$ A large proportion of these deaths could be avoided by quality obstetric and medical care. ${ }^{3}$ However, gaps in the access to quality care remain substantial in many regions,${ }^{4-6}$ despite major efforts to expand access to essential services. ${ }^{7-9}$

One of the most obvious ways to increase access to healthcare is to reduce the distance to health facilities through the construction of additional health centres. While several cross-sectional studies suggest better health outcomes and high utilisation of health services for families living in close proximity to health facilities, ${ }^{10-12}$ evidence on the impact of increased health facility availability on child mortality, antenatal care (ANC) attendance and skilled delivery is inconclusive and somewhat contradictory. ${ }^{13-16}$

Côte d'Ivoire has made major efforts to increase the number of first contact health establishments in the past decade. Between 2012 and 2018, 726 new health facilities have been constructed throughout the country, ${ }^{17} 18$ increasing the total number of primary healthcare (PHC) centres by $41 \%$ from 1753 facilities in 2012 to 2479 facilities in 2018. Over the same period, child mortality declined from 108 to 81 deaths per 1000 live births, ${ }^{19}{ }^{20}$ use of ANC and facility delivery increased respectively from $91 \%$ to $93 \%$ and from $57.4 \%$ to $69.8 \% .^{21}{ }^{22}$ However, little is known regarding the contributions of the national health infrastructure efforts towards these improved health services utilisation and health outcomes.

In this study, we used detailed demographic surveillance data obtained from the Taabo health and demographic surveillance system (HDSS), located in the south-central part of Côte d'Ivoire. Our objective was to assess the extent to which newly established healthcare facilities improved local population health as well as the utilisation of health services.

\section{METHODS}

We followed the Strengthening the Reporting of Observational Studies in Epidemiology (STROBE) cross-sectional reporting guidelines ${ }^{23}$ throughout the manuscript.

\section{Study design}

A quasi-experimental study was conducted to assess the impact of new healthcare facilities on treatment seeking and mortality outcomes. At the beginning of the study 7 out of 13 villages had their own health centre. In 2010, a local committee decided to build four additional health centres. To assess the causal impact of these new facilities, we compared village-level changes in child mortality before and after opening of new facilities to the changes observed in communities with constant health facility access over the same period. All empirical models included village and year fixed effects (intercepts) to rule out confounding by time-invariant unobserved characteristics.

\section{Setting and participants}

This study was conducted in the Taabo HDSS. The Taabo HDSS is located in the south-central part of Côte d'Ivoire and covers a surface area of approximately $980 \mathrm{~km}^{2}$. The area is mainly rural and comprises 13 villages as well as an urban settlement (Taabo-Cité) (figure 1). The primary economic activity of the region is agriculture, dominated by cocoa and rubber but also featuring subsistence crops such as cassavas, plantains, vegetables and yams.

Under-5 mortality was 94 per 1000 children born alive in $2010 .{ }^{24}$ The primary causes of death in the area are malaria $(18.0 \%)$, acute respiratory infections $(15.4 \%)$, HIV/AIDS (11.2\%) and pulmonary tuberculosis $(6.5 \%)$. Non-communicable diseases (NCDs) represented $18.9 \%$ of deaths, mainly due to acute abdomen (5.3\%), while unspecified cardiac diseases, digestive neoplasm and severe malnutrition accounted for less than 3\% each.

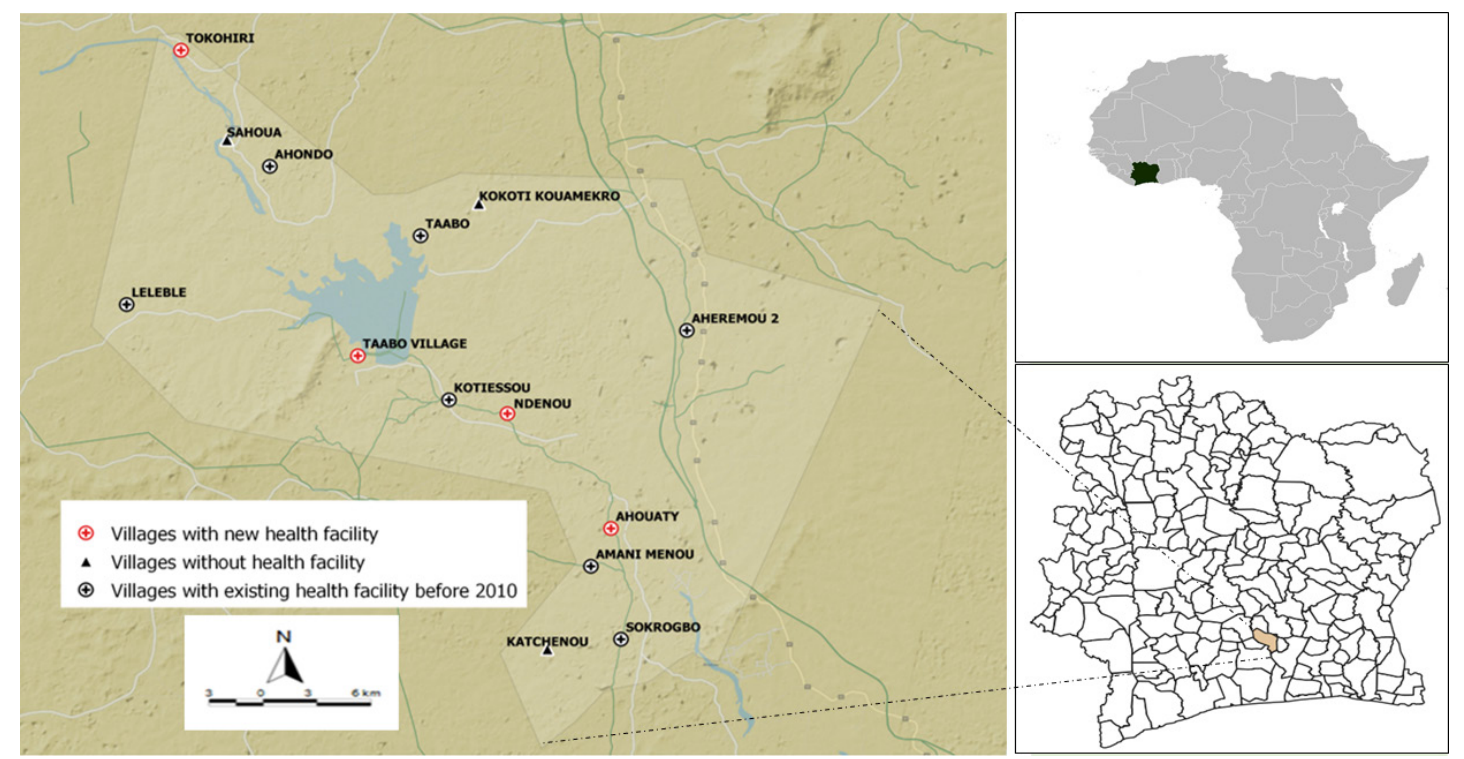

Figure 1 Map of the Taabo health and demographic surveillance system in south-central Côte d'Ivoire. 
Maternal and neonatal conditions accounted for $8.3 \%$ of all deaths. ${ }^{25}$

All women of reproductive age whose pregnancy started and ended between January 2010 and December 2018 and all deaths registered during this 9-year period were included in the analysis. Each household of the Taabo HDSS was visited three times per year for detailed registration of births, deaths, in-migrations, out-migrations and pregnancies. New pregnancies were followed-up longitudinally and all women with a new pregnancy were interviewed using a specific pregnancy questionnaire. This questionnaire includes the date of last menstrual period and pregnancy outcome; hence, facilitating enumerators to be aware of neonatal deaths. Key informants in communities continuously observed and reported any death occurring in the surveillance zone. More detailed information on routine monitoring activities have been described elsewhere. ${ }^{24}$ All individuals registered and living in the Taabo HDSS between 2010 and 2018 were included in the study.

\section{The Fairmed health infrastructure intervention programme}

As mentioned above, only 7 of the 13 villages had their own health facilities in 2010. These PHC centres were supported by a 12-bed hospital in Taabo-Cité. In 2010, Fairmed, a non-governmental organisation, launched activities to reduce mortality and morbidity due to malaria and neglected tropical diseases.

During the initial engagement of stakeholders, distance to facilities was highlighted by community members as the primary health system constraint, and construction of new health centres in the area was requested. Based on population size and access to facilities in 2010, four out of the six villages without health centres in 2010 were selected for new primary care health facilities. These facilities were designed to run by a nurse or midwife and included a dispensary, a small maternity ward and a pharmacy.

Primary care facilities were supposed to offer the local population a minimum package of essential health services including routine immunisation of children, curative care for common ailments, prenatal and postnatal consultations, and family planning, deliveries assistance, prevention of mother-to-child transmission of HIV, as well as the promotion of essential family practices with the support of community relays.

The first new health centre was opened in Tokohiri in May 2013. In January 2015, a new health centre started its operations in Taabo-Village. Finally, in January and February 2017, new health centres were opened in Ahouaty and N'Denou. Figure 1 illustrates the location of these new health facilities, while figure 2 illustrates the timeline of the project.

\section{Study variables}

The primary outcome variables were ANC attendance, facility delivery and all-cause mortality. ANC attendance was a binary variable taking value 0 if the woman had not made any prenatal consultation and value 1 if she made at least one prenatal consultation. Facility delivery was a binary value with 0 for all deliveries outside a health facility and value 1 for all deliveries at a health facility (health centre or hospital). We defined four age-specific mortality variables for children: (1) neonatal mortality (ie, the probability of dying within the first 30 days of life); (2) postneonatal infant mortality (ie, the probability of dying between days 30 and 364 of life); (3) infant mortality (ie, the probability of dying before the first birthday) and (4) child mortality (ie, the probability of dying between the first and fifth birthdays).$^{26}$ For adults, we analysed mortality by age groups: $18-39,40-59,60-79$ and $\geq 80$ years.

To minimise the risk of confounding through other factors that may have changed over time, we controlled for age and sex of child, twin status, child year of birth and mother and household characteristics (maternal age, religion, education, marital status, number of previous pregnancies and household socioeconomic status) in all child mortality models. Health facility delivery and ANC attendance were adjusted only for mother and household characteristics (maternal age, religion, education, marital status, number of previous pregnancies and household socioeconomic status).

We used principal component analysis of household assets to divide households into wealth quintile (ie, poorest, poor, medium, rich and richest). ${ }^{27}$

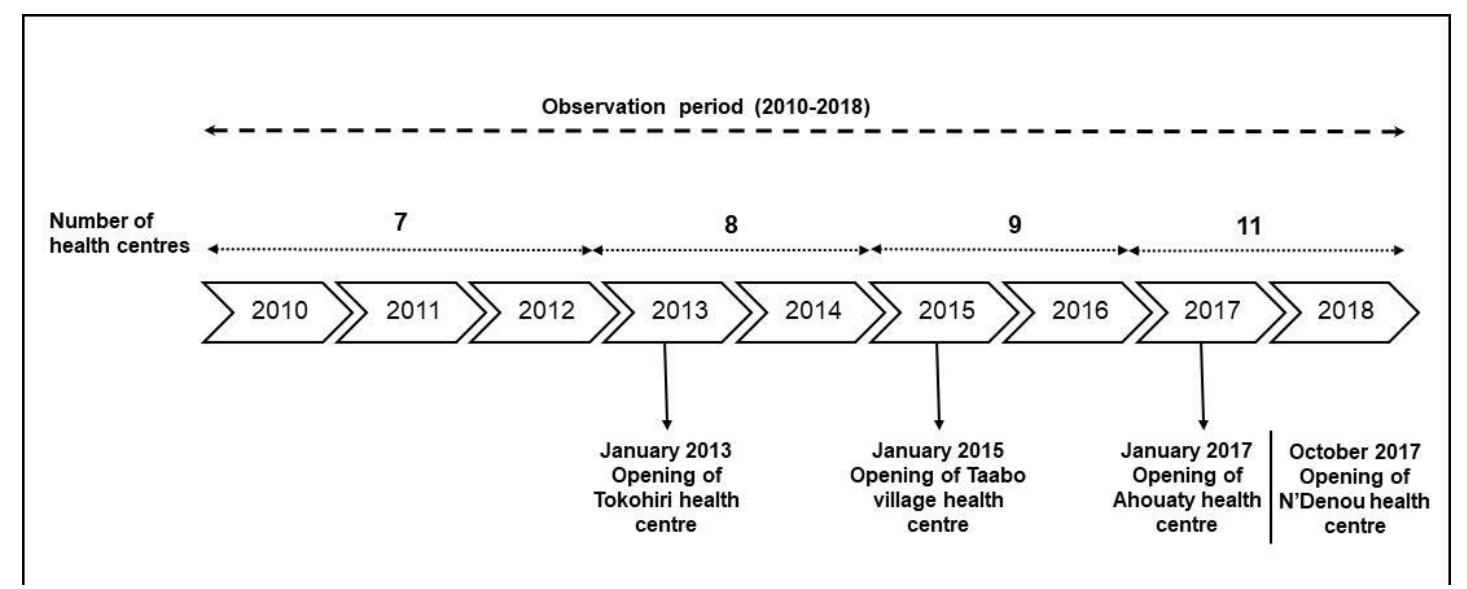

Figure 2 Health facility coverage in the Taabo HDSS from 2010 to 2018. HDSS, health and demographic surveillance. 
The primary exposure variable of interest was the availability of a health facility in the village of residence during the exposure period. For the four period-specific mortality variables (ie, neonatal, postneonatal, infant and child mortality), local facility availability was coded as 1 if the facility was operational in the month of birth. For ANC attendance and facility delivery, local facility availability was coded as 1 if the facility was operational when the pregnancy started.

\section{Statistical analysis}

Data collected during this study were cross-checked and managed using a household registration system implemented in Windev V.12.0 (PC Soft; Montpellier, France). We also computed distance to the nearest facility for all households using the Statageodist package. ${ }^{28}$ We then displayed minimum, average and maximum for distance before and after the health centre was operational in each village.

Descriptive statistics of the study sample included means, minimum and maximum of quantitative variables and frequencies $(\%)$ of categorical variables. We used Cox proportional hazards model to estimate impacts on mortality. We also used instrumental variable regression models to estimate the impact of distance on child survival, using the local facility availability as predictors of household distance. In a sensitivity analysis, we employed linear probability models to ensure the robustness of the postneonatal mortality outcomes with respect to the empirical model.

We used multivariate logistic regression with clustering at village and year level to investigate the relationship between ANC attendance, health facility delivery and local health centre availability.

All models included child and mother characteristics as well as village and year fixed effects (intercepts) to rule out confounding by time-invariant unobserved characteristics. Standard errors were corrected to allow for residual correlation both at the household and community level using Huber's cluster-robust variance estimator. ${ }^{29}$ All statistical analyses were performed in Stata V.15.0 (StataCorp).

\section{Patient and public involvement statement}

Patients were not involved in the design and implementation of this study.

\section{RESULTS}

\section{Study sample and sociodemographic characteristics}

Between January 2010 and December 2018, a total of 14132 pregnancies were registered in the Taabo HDSS. Online supplemental appendix table 1 presents the key characteristics of this sample. Most of the women were in a common-law or married union; $72.0 \%$ attended at least one ANC consultation and $52.3 \%$ gave birth in a health facility. Sixty-nine percent of the women were aged between 20 and 34 years. Only $30 \%$ of the women had completed elementary school, while $56.0 \%$ had never attended school.

Table 1 presents crude numbers of deaths and mortality rates per subgroup and 1000 person-years. A total of 440973 person-year observations were included in the mortality analysis. There were 2957 deaths reported in the study period. Overall mortality was 6.7 (95\% CI 6.5 to 7.0) deaths per 1000 person-years, with a higher rate in males compared with females (7.3 vs 6.1 deaths per 1000 person-years). Highest mortality rates (8.1 deaths per $1000,95 \%$ CI 7.5 to 8.7 ) were observed in the poorest households and lowest mortality rates (4.9 deaths per $1000,95 \%$ CI 4.5 to 5.4 ) were observed among households in the highest asset quintile. A similar socioeconomic gradient was observed for education, with 12.2 deaths per 1000 for individuals who had never attended school, compared with 3.0 per 1000 for individuals with completed secondary education.

As shown in figure 3, slightly less than half of the child deaths were infant deaths (age at death $<1$ year), and $25 \%$ of death occurred between 12 and 23 months of age.

As regards the association of mortality and distance to the nearest health facility, smaller distance was associated with lower mortality (<1 km: 6.1 (95\% CI 5.7 to 6.6$), 1-4$ $\mathrm{km}: 6.7$ (95\% CI 6.4 to 7.0$)$ and $\geq 5 \mathrm{~km}: 7.6$ (95\% CI 7.0 to 8.2) deaths per 1000 person-years).

\section{Health facilities opening and change in physical access with distance}

Table 2 shows distance to the nearest health facility before and after the opening of the new health centres in Ahouaty, N'Denou, Taabo-Village and Tokohiri. Across the four villages, the average distance from households to the nearest health facility was reduced from $5.5 \mathrm{~km}$ before to $2.8 \mathrm{~km}$ after the opening of the new health centres. The largest reduction in average distance to health facility was observed in Tokohiri $(6.4 \mathrm{~km})$, followed by Taabo-Village $(4.1 \mathrm{~km})$. In Ahouaty and N'Denou the average distance was reduced from $3.4 \mathrm{~km}$ to $1.5 \mathrm{~km}$ and from $2.2 \mathrm{~km}$ to $1.3 \mathrm{~km}$, respectively. An overview of the households' location in relation to the nearest health facility prior to the construction of the new health centres is presented in online supplemental appendix figure 1 .

\section{Effects of health facility opening on ANC and facility delivery}

Table 3 presents the estimated causal impact of health facility opening and ANC and facility delivery. On average, new facilities increased the odds of ANC attendance by $24 \%$ (OR 1.24, 95\% CI 0.96 to $1.60, \mathrm{p}<0.1$ ) in unadjusted models. However, after adjusting for socio-demographic characteristics of women, this difference became statistically non-significant (OR 1.21, 95\% CI 0.91 to $1.61, \mathrm{p}$ $>0.05)$. We found no evidence of increased use of institutional deliveries after new facility opening (OR 0.87, 95\% CI 0.70 to 1.07 in adjusted models).

Figure 4 shows the total number of deaths from 2010 to 2018 in the four villages of the Taabo HDSS where new 
Table 1 Person-year structure, total number of deaths and mortality rates by sociodemographic characteristics, 2010-2018

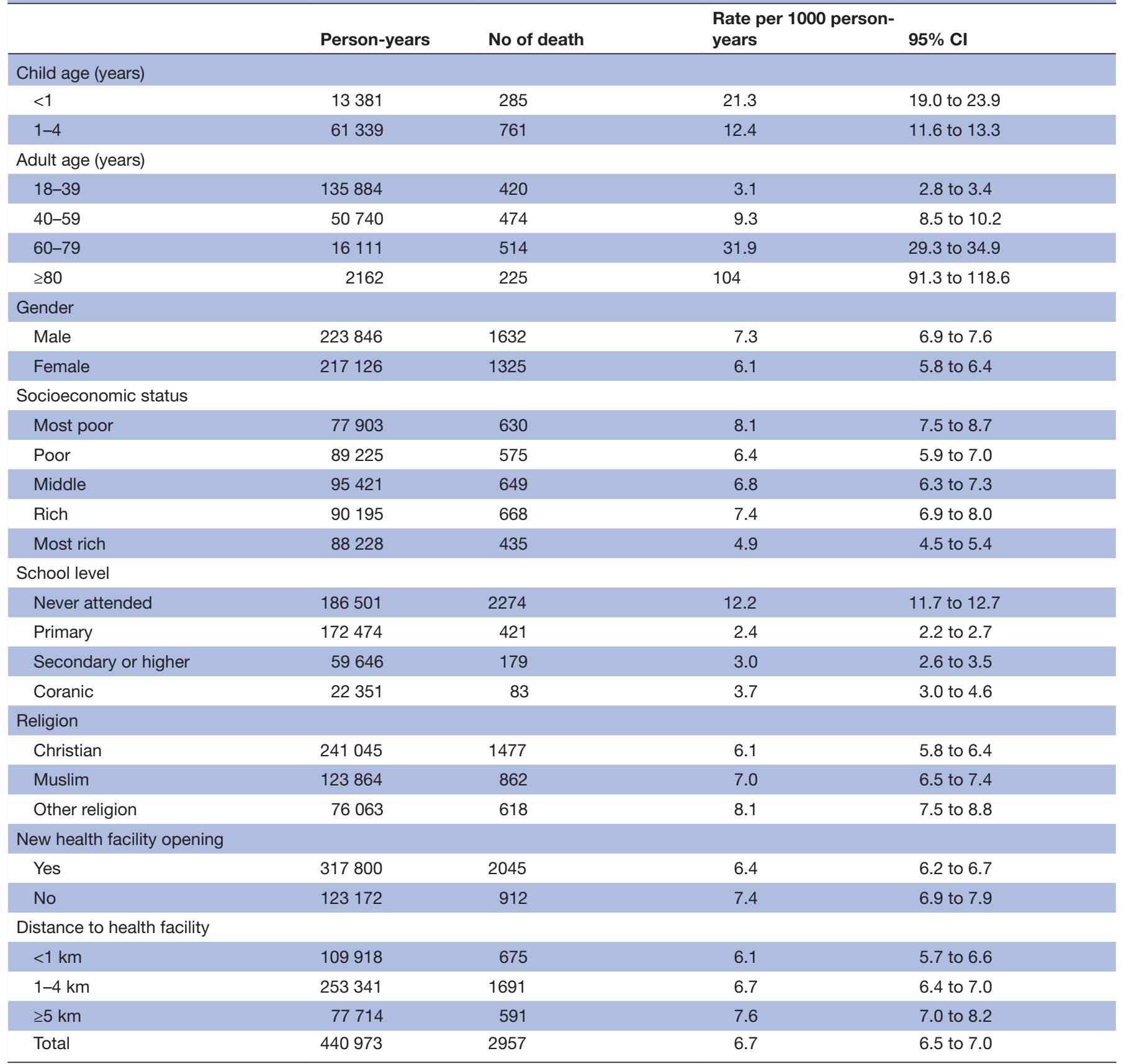

health facilities were constructed. The vertical red line in each graph indicates when the health facility opened.

Table 4 presents the main impacts on child survival. New facilities reduced the likelihood of post-neonatal infant death by $46 \%$ (HR $0.56,95 \% \mathrm{Cl} 0.31$ to 0.99 , p <0.05). No impact was found on neonatal and child mortality.

Table 5 shows estimated impacts on adult mortality. We observed no statistically significant associations ( $p>0.05)$ between health facility opening and adults mortality.

\section{Sensitivity analysis}

Table 6 summarises results from a sensitivity analysis, using linear probability models restricted to post-neonatal mortality to ensure the robustness of the post-neonatal mortality outcomes with respect to the empirical model. On average, we found that each additional $\mathrm{km}$ in distance increased post-neonatal mortality by 2 deaths per 1000 $($ Coef $=0.002,95 \%$ CI 0.000 to $0.004, \mathrm{p}<0.05$; table 6$)$.

\section{DISCUSSION}

In this study, we used longitudinal surveillance data from a well-characterised population-based cohort in the Taabo HDSS in south-central Côte d'Ivoire to estimate the impact of newly constructed health facilities on the utilisation of essential maternal health services as well as child and adult mortality. Even though the 
Distribution of age of death by gender
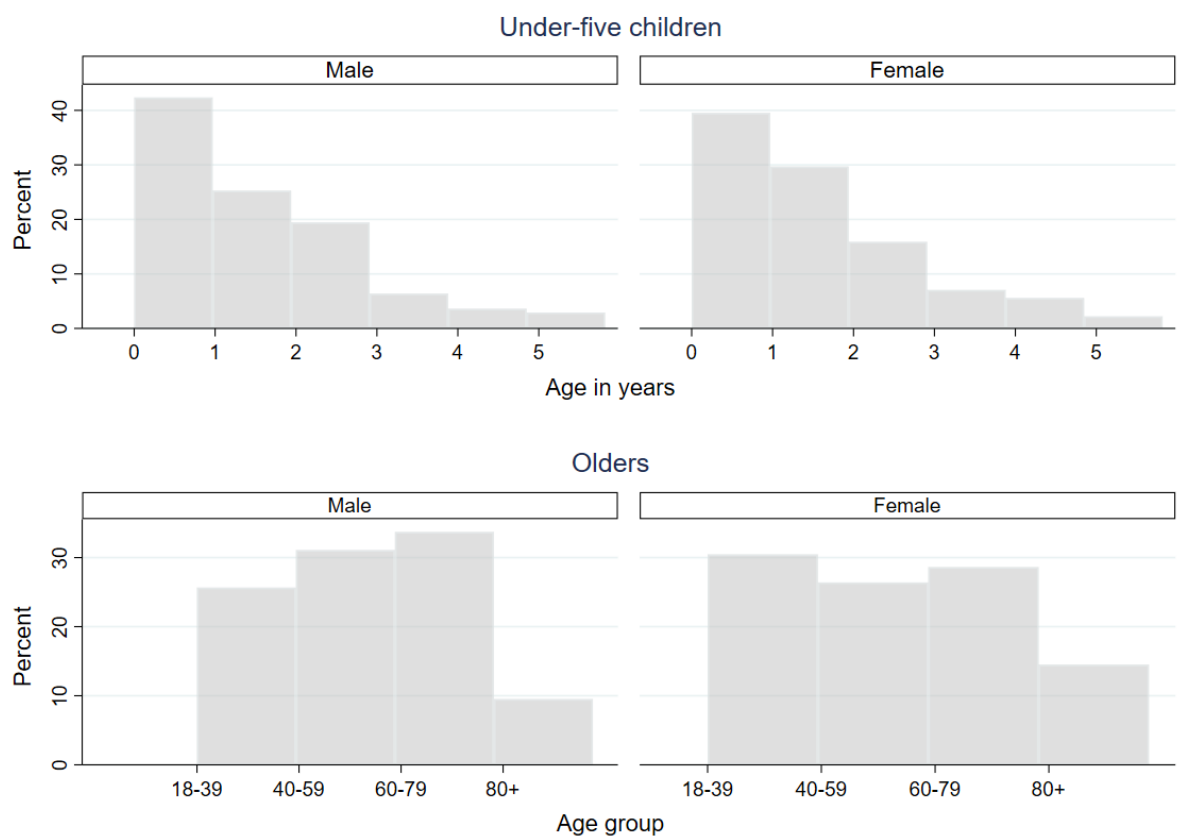

Figure 3 Distribution of age at death, stratified by gender and age.

construction of new facilities was initiated in response to local demand and a local needs assessment, overall impacts seem relatively limited. Specifically, and contrary to previous cross-sectional studies, ${ }^{30} 31$ we found no changes in mortality for the neonatal period (where most child death occur) or for adults. For adults,
$80.5 \%$ of deaths have been attributed to NCDs, which are not generally supported by PHC centres. ${ }^{25}$ The lack of a mortality impact on adults could thus be partly explained by health systems in low-income and middleincome countries being still relatively ill prepared for chronic disease management. ${ }^{32} 33$

\begin{tabular}{|c|c|c|c|}
\hline Village & Min & Mean & Max \\
\hline \multicolumn{4}{|l|}{ Ahouaty } \\
\hline Before health facility opening & 2.10 & 3.43 & 4.24 \\
\hline After health facility opening & 0.46 & 1.53 & 2.29 \\
\hline Difference & -1.64 & -1.90 & -1.95 \\
\hline \multicolumn{4}{|l|}{ N'Denou } \\
\hline Before health facility opening & 1.38 & 2.20 & 7.63 \\
\hline After health facility opening & 0.05 & 1.25 & 1.74 \\
\hline Difference & -1.32 & -0.96 & -5.88 \\
\hline \multicolumn{4}{|l|}{ Taabo-Village } \\
\hline Before health facility opening & 1.28 & 6.83 & 9.45 \\
\hline After health facility opening & 0.30 & 2.77 & 7.34 \\
\hline Difference & -0.99 & -4.06 & -2.12 \\
\hline \multicolumn{4}{|l|}{ Tokohiri } \\
\hline Before health facility opening & 3.55 & 9.42 & 12.88 \\
\hline After health facility opening & 0.56 & 3.02 & 8.53 \\
\hline Difference & -3.00 & -6.40 & -4.35 \\
\hline \multicolumn{4}{|l|}{ Total } \\
\hline Before health facility opening & 1.28 & 5.47 & 12.88 \\
\hline After health facility opening & 0.05 & 2.76 & 8.53 \\
\hline Difference & -1.23 & -2.71 & -4.35 \\
\hline
\end{tabular}


Table 3 Estimated impact of facility opening on antenatal care attendance and institutional delivery

\begin{tabular}{|c|c|c|c|c|}
\hline \multirow[b]{3}{*}{ Variables } & \multicolumn{2}{|c|}{ Antenatal care attendance } & \multicolumn{2}{|c|}{ Institutional delivery } \\
\hline & Unadjusted & Adjusted & Unadjusted & Adjusted \\
\hline & OR (95\% Cl) & OR $(95 \% \mathrm{Cl})$ & OR (95\% Cl) & OR (95\% Cl) \\
\hline Yes & $1.24^{\star}(0.96$ to 1.60$)$ & $1.21(0.91$ to 1.61$)$ & 0.87 (0.71 to 1.06$)$ & $0.87(0.70$ to 1.07$)$ \\
\hline Observations & 14132 & 14132 & 14132 & 14132 \\
\hline
\end{tabular}

All estimates are based on logistic regressions with clustering at the village-year level. OR are displayed with 95\% Cls in parentheses. Unadjusted models control for year and village fixed effects only. Adjusted models control for mother's characteristics as well as village and year fixed effects. ${ }^{*} \mathrm{P}<0.1,{ }^{* *} \mathrm{p}<0.01,{ }^{* * *} \mathrm{p}<0.001$.

The lack of impact on neonatal mortality seems less surprising given the lack of impact on institutional deliveries. Limited change in institutional deliveries is likely due to relatively limited infrastructure available at the new health centres; this in turn limits the health personnel's ability to deal with complicated deliveries that cause most of the neonatal deaths. ${ }^{34}{ }^{35}$ A recent study from Malawi ${ }^{12}$ shows that having a high-quality facility in close proximity to households is associated with large reductions in neonatal mortality, but that similar patterns cannot be observed for lower quality health facilities. Quality care remains a key challenge in many settings, ${ }^{36} 37$ and is likely of particular importance for neonatal mortality. ${ }^{31}$ This may be different for the post-neonatal period, where timely treatment may be of paramount importance, and basic treatment for the most common conditions (malaria and respiratory infections) can be provided even by health centres with very limited supplies.

The lack of impact of new health facilities on ANC utilisation, where distance has been highlighted as key barrier to access, is somewhat more surprising than the mixed impacts on mortality. Several studies have highlighted the associations between travel time and treatment seeking behaviour, and argued that mortality penalties for children and adults can be lowered through easier access. ${ }^{153038} 39$ On the other hand, our results are well aligned with a study from Malawi, which also found that newly constructed facilities in the 1990s resulted neither in changes in utilisation of ANC and skilled delivery, nor in changes in mortality outcomes. ${ }^{15}$ The lack of impact of new health facilities on care utilisation is not explained by high baseline levels that would not allow

Total number of deaths over time
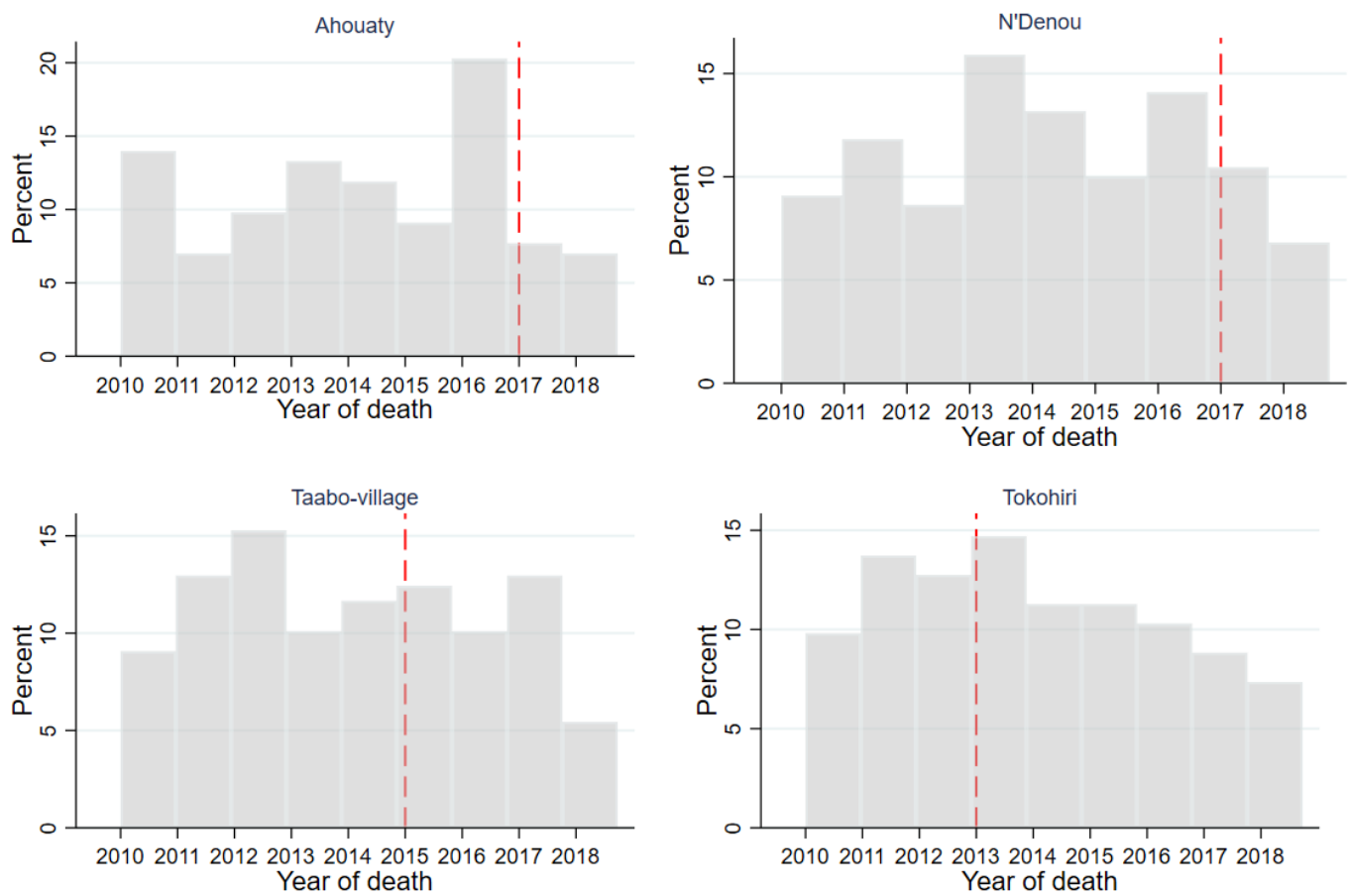

Figure 4 Number of all ages deaths over time in the four villages with new health facilities. 
Table 4 Estimated impact of facility opening on child mortality

\begin{tabular}{|c|c|c|c|c|}
\hline \multirow[b]{3}{*}{ Variable } & \multicolumn{3}{|c|}{ Under-5 mortality } & \multirow[b]{2}{*}{ Child } \\
\hline & Neonatal & Post-neonatal & Infant & \\
\hline & HR $(95 \% \mathrm{Cl})$ & HR $(95 \% \mathrm{Cl})$ & HR $(95 \% \mathrm{Cl})$ & HR $(95 \% \mathrm{Cl})$ \\
\hline Yes & 1.29 (0.41 to 4.02$)$ & $0.56^{\star \star}(0.31$ to 0.99$)$ & $0.65^{\star}$ (0.39 to 1.08$)$ & 1.11 (0.68 to 1.82$)$ \\
\hline \multicolumn{5}{|l|}{ Child's sex: male } \\
\hline Female & 1.31 (0.81 to 2.12$)$ & 1.04 (0.82 to 1.33$)$ & $1.08(0.87$ to 1.34$)$ & 1.06 (0.85 to 1.34$)$ \\
\hline \multicolumn{5}{|l|}{ Twin: no } \\
\hline Yes & $14.00^{\star \star \star}(6.21$ to 31.57$)$ & $2.12^{\star \star}(1.04$ to 4.31$)$ & $3.72^{\star \star \star}(2.24$ to 6.19$)$ & 1.45 (0.54 to 3.90$)$ \\
\hline \multicolumn{5}{|c|}{ Number of previous pregnancies } \\
\hline Pregnancies & $1.15^{\star}(1.00$ to 1.32$)$ & $1.07^{\star \star}(1.00$ to 1.15$)$ & $1.09^{\star \star \star}(1.02$ to 1.16$)$ & 0.98 (0.92 to 1.05$)$ \\
\hline \multicolumn{5}{|l|}{ Maternal age } \\
\hline Age & $0.94^{\star \star}(0.89$ to 0.99$)$ & $0.98^{\star \star}(0.95$ to 1.00$)$ & $0.97^{\star \star \star}(0.95$ to 0.99$)$ & $0.99(0.97$ to 1.01$)$ \\
\hline Rich & 0.75 (0.36 to 1.57$)$ & 1.01 (0.68 to 1.49$)$ & 0.92 (0.65 to 1.30$)$ & 0.87 (0.60 to 1.27$)$ \\
\hline Most rich & $0.47(0.1$ to 1.26$)$ & 1.09 (0.68 to 1.75$)$ & $0.92(0.60$ to 1.40$)$ & $0.92(0.59$ to 1.45$)$ \\
\hline Observations & 5478 & 24845 & 30323 & 79288 \\
\hline
\end{tabular}

All estimates are based on Cox regressions. Coefficients displayed are HRs with $95 \%$ Cls in parentheses. All models control for child and mother characteristics as well as year, village and mother fixed effects.

Postneonatal The probability of dying between the first 30 days and 364 days of life.

**** $p<0.01,{ }^{* *} p<0.05,{ }^{*} p<0.1$.

Child, the probability of dying between the first and fifth birthdays; Infant, the probability of dying before the first birthday; Neonatal, the probability of dying within the first 30 days of life.

for any improvements. Less than three-quarter $(72.0 \%)$ of women had attended at least one prenatal consultation, while slightly more than half $(52.3 \%)$ had given birth in a health facility in our sample. Estimates from the national Demographic and Health Survey conducted in 2012 look fairly similar. ${ }^{22}$ Research from Côte d'Ivoire suggests that lack of access to supplements and drugs may be a key barrier to ANC access. ${ }^{40}$ It is also conceivable

Table 5 Estimated impact of facility opening on adult mortality

\begin{tabular}{|c|c|c|c|c|}
\hline \multirow[b]{3}{*}{ Variable } & \multirow[b]{2}{*}{$18-39.9$} & \multicolumn{2}{|c|}{ Age groups } & \multirow[b]{2}{*}{$80+$} \\
\hline & & $40-59.9$ & $60-79.9$ & \\
\hline & HR $(95 \%$ Cl) & HR (95\% Cl) & HR (95\% Cl) & HR $(95 \% \mathrm{Cl})$ \\
\hline Yes & 1.22 (0.75 to 1.99$)$ & 0.77 (0.50 to 1.19$)$ & 0.97 (0.64 to 1.47$)$ & $0.90(0.47$ to 1.72$)$ \\
\hline \multicolumn{5}{|l|}{ Gender: Male } \\
\hline Poor & $0.73^{*}(0.53$ to 1.00$)$ & $0.77^{\star}(0.57$ to 1.03$)$ & 0.95 (0.70 to 1.30$)$ & $0.90(0.49$ to 1.64$)$ \\
\hline Middle poor & 0.81 (0.59 to 1.11$)$ & $0.73^{\star \star}(0.54$ to 0.99$)$ & 1.02 (0.76 to 1.37$)$ & $0.99(0.57$ to 1.73$)$ \\
\hline Rich & 0.80 (0.57 to 1.11$)$ & 0.81 (0.61 to 1.09$)$ & 0.95 (0.70 to 1.30$)$ & $0.97(0.55$ to 1.71$)$ \\
\hline Most rich & 0.92 (0.62 to 1.38$)$ & $0.51^{\star \star *}(0.33$ to 0.78$)$ & 0.90 (0.61 to 1.33$)$ & 1.03 (0.54 to 1.97$)$ \\
\hline Observations & 343088 & 129636 & 40826 & 4698 \\
\hline
\end{tabular}

All estimates are based on Cox regressions. Coefficients displayed are HRs with $95 \%$ Cls in parentheses. All models control sociodemograpthic characteristics as well as year and village fixed effects

${ }^{\star * \star *} p<0.01,{ }^{\star *} p<0.05,{ }^{*} p<0.1$, 
Table 6 Estimated linear effect of health facility opening and distance on post-neonatal and infant mortality

\begin{tabular}{|c|c|c|c|c|}
\hline \multirow[b]{3}{*}{ Variables } & \multicolumn{2}{|c|}{ Postneonatal mortality } & \multicolumn{2}{|c|}{ Infant mortality } \\
\hline & Model (1) & Model (2) & Model (3) & Model (4) \\
\hline & Coef $(95 \% \mathrm{Cl})$ & Coef $(95 \% \mathrm{Cl})$ & Coef $(95 \% \mathrm{Cl})$ & Coef $(95 \% \mathrm{Cl})$ \\
\hline Yes & $-0.007^{\star \star \star}(-0.010$ to to 0.003$)$ & $-0.011^{\star \star \star}(-0.018$ to to 0.004$)$ & $-0.005^{\star \star}(-0.009$ to to 0.001$)$ & $-0.006^{*}(-0.012,0.001)$ \\
\hline Observations & 25047 & 27827 & 30531 & 33749 \\
\hline \multicolumn{5}{|l|}{ Distance } \\
\hline Distance & $0.002^{\star \star \star}(0.001,0.003)$ & $0.002^{\star *}(0.000,0.004)$ & $0.002^{\star \star \star}(0.000,0.003)$ & $0.002^{\star \star}(0.000,0.003)$ \\
\hline Observations & 25047 & 25047 & 30531 & 30531 \\
\hline R-squared & 0.002 & 0.002 & 0.004 & 0.004 \\
\hline
\end{tabular}

All estimates are based on linear regressions. Coefficients are displayed with $95 \% \mathrm{Cls}$ in parentheses.

Model 1 and model 3 control for child and mother characteristics as well as village and round fixed effects only.

Model 2 and model 4 control for child, mother characteristics, village, round as well as mother fixed effects.

${ }^{* * \star *} p<0.01,{ }^{* *} p<0.05,{ }^{*} p<0.1$.

that additional out-of-pocket payments contribute to the generally low demand for ANC services. ${ }^{41}{ }^{42}$ In order to increase beneficiary satisfaction and utilisation of the health centres, incentives (availability and utilisation of health services, posting and respect of fees for healthcare procedures, availability of drugs and strategic inputs, existence and functionality of management committees, and the conduct of sensitisation sessions on the priority health problems of the village) have more recently been put in place.

The main strength of our study is the continuous prospective collection of surveillance data through the HDSS, which allowed to closely monitor and measure changes in healthcare seeking behaviours and health outcomes over time. The study also benefits from the central decision on the timing and location of new facilities, providing a plausible natural experiment for assessing facility impacts.

Nevertheless, our study is subject to certain limitations. First, the results are based on only a small number $(n=4)$ of new health facilities constructed. Even though we believe that these facilities are fairly representative in the national efforts in Côte d'Ivoire to strengthen PHC, observed impacts may be different in other settings. It is also conceivable that average health facility distances prior to the construction of facilities may be larger in other areas. In our setting, average distance to health facilities prior to the opening of new centres was $5 \mathrm{~km}$. These distances are likely substantially larger in other, less densely populated settings, even though some recent papers suggested that most households now live fairly close to facilities in SSA. ${ }^{30} 43$ Second, from a quality of care perspective, both equipment and staffing provided to facilities are of critical importance. On average, the four new health centres had only one staff member and limited diagnostic tools. Hence, the estimates presented here lack representation for an establishment of larger and better equipped places. Third, we only had a relatively small number of child (postinfancy under 5) deaths in our sample, limiting our statistical power. Larger studies may be able to detect smaller improvements. Fourth, we opted for Euclidean distances calculation from the household to the nearest health facility. This likely underestimates the true distance and travel time on the ground, and may thus bias our distance estimates. ${ }^{144}$

\section{CONCLUSION}

Our study suggests that local construction of new health centres in a mainly rural part of south-central Côte d'Ivoire may have only relatively limited impact on healthcare utilisation and overall population health. More research will be needed to better understand the somewhat limited impacts seen in this study as well as to identify the health infrastructure needed more generally for improving health outcomes in this setting.

\section{Author affiliations}

${ }^{1}$ Centre Suisse de Recherches Scientifiques en Côte d'Ivoire, Abidjan, Côte d'Ivoire

${ }^{2}$ Swiss Tropical and Public Health Institute, Allschwil, Switzerland

${ }^{3}$ University of Basel, Basel, Switzerland

${ }^{4}$ Unité de Formation et de Recherche Biosciences, Université Félix HouphouëtBoigny, Abidjan, Côte d'Ivoire

Acknowledgements We thank the population in the four study villages for their collaboration, the Taabo HDSS team and field enumerators for data entry and staff management, and to the key informants for their untiring help in the field, particularly for data collection and processing. We are most grateful to Fairmed, the Health District of Tiassalé, the Taabo-Cité Public Hospital, the Centre Suisse de Recherches Scientifiques en Côte d'Ivoire, the Université Félix Houphouët-Boigny and the Swiss Tropical and Public Health Institute for the partnership and vision, which facilitated the establishment of the Taabo HDSS some 15 years ago.

Contributors Conceived and designed the study: SK, BB, EKN'G and JU; conducted the study and collected data: SK, BB, EKN'G and JU; performed statistical analyses and summarised the data in tabular and graphical forms: SK and GF; interpreted data and prepared a first manuscript draft: SK and GF; provided important intellectual input to interpretation of findings and manuscript writing: SK, GF, BB, NP-H, EKN'G and JU; reviewed and revised manuscript draft based on comments made by all authors and reviewers: SK, BB, NP-H, ENK'G, JU and GF; supervised the 
project and responsible for the overall content as the guarantor: GF; All authors read and approved the final manuscript.

Funding The authors have not declared a specific grant for this research from any funding agency in the public, commercial or not-for-profit sectors.

Map disclaimer The inclusion of any map (including the depiction of any boundaries therein), or of any geographic or locational reference, does not imply the expression of any opinion whatsoever on the part of BMJ concerning the legal status of any country, territory, jurisdiction or area or of its authorities. Any such expression remains solely that of the relevant source and is not endorsed by BMJ. Maps are provided without any warranty of any kind, either express or implied.

Competing interests None declared.

Patient consent for publication Not applicable.

Ethics approval We obtained an umbrella agreement for longitudinal monitoring of vital statistics (pregnancy, birth, death, in-migration and out-migration), healthrelated research and public health interventions by the Comité National d'Ethique et de Recherche (CNER) in Côte d'Ivoire (reference no. 1086 MSHD/CNEF) and the Ethikkommission beider Basel (EKBB) in Switzerland (reference no. 316/08). Patient data were deidentified before access by study authors.

Provenance and peer review Not commissioned; externally peer reviewed.

Data availability statement Data are available on reasonable request. All data relevant to the study are included in the article or uploaded as online supplemental information. Data are available on request. All data relevant to the study are included in the article or uploaded as online supplemental information. Any further data are available on request.

Supplemental material This content has been supplied by the author(s). It has not been vetted by BMJ Publishing Group Limited (BMJ) and may not have been peer-reviewed. Any opinions or recommendations discussed are solely those of the author(s) and are not endorsed by BMJ. BMJ disclaims all liability and responsibility arising from any reliance placed on the content. Where the content includes any translated material, BMJ does not warrant the accuracy and reliability of the translations (including but not limited to local regulations, clinical guidelines, terminology, drug names and drug dosages), and is not responsible for any error and/or omissions arising from translation and adaptation or otherwise.

Open access This is an open access article distributed in accordance with the Creative Commons Attribution Non Commercial (CC BY-NC 4.0) license, which permits others to distribute, remix, adapt, build upon this work non-commercially, and license their derivative works on different terms, provided the original work is properly cited, appropriate credit is given, any changes made indicated, and the use is non-commercial. See: http://creativecommons.org/licenses/by-nc/4.0/.

\section{ORCID iD}

Siaka Koné http://orcid.org/0000-0002-1630-5963

\section{REFERENCES}

1 You D, Hug L, Ejdemyr S, et al. Global, regional, and national levels and trends in under-5 mortality between 1990 and 2015, with scenario-based projections to 2030: a systematic analysis by the UN Inter-Agency Group for Child Mortality Estimation. Lancet 2015;386:2275-86.

2 Liu L, Oza S, Hogan D, et al. Global, regional, and national causes of under-5 mortality in 2000-15: an updated systematic analysis with implications for the Sustainable Development Goals. Lancet 2016;388:3027-35.

3 Lawn JE, Lee ACC, Kinney M, et al. Two million intrapartum-related stillbirths and neonatal deaths: where, why, and what can be done? Int J Gynaecol Obstet 2009;107:S5-19.

4 GBD 2016 Healthcare Access and Quality Collaborators. Measuring performance on the healthcare access and quality index for 195 countries and territories and selected subnational locations: a systematic analysis from the Global Burden of Disease Study 2016. Lancet 2018;391:2236-71.

5 Bhutta ZA, Das JK, Bahl R, et al. Can available interventions end preventable deaths in mothers, newborn babies, and stillbirths, and at what cost? Lancet 2014;384:347-70.

6 Escamilla V, Calhoun L, Winston J, et al. The role of distance and quality on facility selection for maternal and child health services in urban Kenya. J Urban Health 2018;95:1-12.

7 Liu L, Leslie HH, Joshua M, et al. Exploring the association between sick child healthcare utilisation and health facility quality in Malawi: a cross-sectional study. BMJ Open 2019;9:e029631.
8 WHO. World Health Report 2013: Research for Universal Health Coverage, 2013

9 World Health Organization and International Bank for Reconstruction and Development / The World Bank. Tracking Universal Health Coverage: 2017 Global Monitoring Report, 2017.

10 Buor D. Analysing the primacy of distance in the utilization of health services in the Ahafo-Ano South district, Ghana. Int J Health Plann Manage 2003;18:293-311.

11 Gao X, Kelley DW. Understanding how distance to facility and quality of care affect maternal health service utilization in Kenya and Haiti: a comparative geographic information system study. Geospat Health 2019;14:690.

12 Leslie $\mathrm{HH}$, Fink $\mathrm{G}$, Nsona $\mathrm{H}$, et al. Obstetric facility quality and newborn mortality in Malawi: a cross-sectional study. PLoS Med 2016;13:e1002151.

13 Doctor HV, Nkhana-Salimu S, Abdulsalam-Anibilowo M. Health facility delivery in sub-Saharan Africa: successes, challenges, and implications for the 2030 Development Agenda. BMC Public Health 2018;18:765.

14 Okwaraji YB, Edmond KM. Proximity to health services and child survival in low- and middle-income countries: a systematic review and meta-analysis. BMJ Open 2012;2:e001196.

15 Quattrochi JP, Hill K, Salomon JA, et al. The effects of changes in distance to nearest health facility on under-5 mortality and health care utilization in rural Malawi, 1980-1998. BMC Health Serv Res 2020;20:899.

16 Rutherford ME, Mulholland K, Hill PC. How access to health care relates to under-five mortality in sub-Saharan Africa: systematic review. Trop Med Int Health 2010;15:508-19.

17 Malmberg B, Lindh T. Demographically based Global Income Forecasts up to the Year 2050. Stockholm, Institute for Futures Studies, Working Paper, 2004.

18 Prskawetz A, Kögel T, Sanderson WC. The Effects of Age Structure on Economic Growth: An Application of Probabilistic Forecasting in India. In: Vienna Institute of Demography, Working Papers, 2004.

19 UNICEF, WHO, The World Bank Group, UN Population Division. Levels \& Trends in Child Mortality: Report 2019. Estimates Developed by the UN Inter-agency Group for Child Mortality Estimation, 2019.

20 UNICEF, WHO, The World Bank Group, UN Population Division. Levels \& Trends in Child Mortality: Report 2013. Estimates Developed by the UN Inter-Agency Group for Child Mortality Estimation, 2013.

21 Institut National de la Statistique (INS) et Fonds des Nations Unies pour I'Enfance (UNICEF). Enquête par Grappes Indicateurs Multiples 2016-17, Rapport sur les Résultats de l'Enquête. Abuja, Nigeria: INS et UNICEF, 2017.

22 Institut National de la Statistique (INS) et ICF International. Enquête Démographique et de Santé et Indicateurs Multiples de Côte d'Ivoire 2011-2012. Calverton, Maryland, USA: INS et ICF International, 2012.

23 von Elm E, Altman DG, Egger M, et al. Strengthening the reporting of observational studies in epidemiology (STROBE) statement: guidelines for reporting observational studies. BMJ 2007;335:806-8.

24 Koné S, Baikoro N, N'Guessan Y, et al. Health \& Demographic Surveillance System Profile: The Taabo Health and Demographic Surveillance System, Côte d'Ivoire. Int J Epidemiol 2015;44:87-97.

25 Koné S, Fürst T, Jaeger FN, et al. Causes of death in the Taabo health and demographic surveillance system, Côte d'Ivoire, from 2009 to 2011. Glob Health Action 2015;8:27271.

26 Rajaratnam JK, Marcus JR, Flaxman AD, et al. Neonatal, postneonatal, childhood, and under-5 mortality for 187 countries, 1970-2010: a systematic analysis of progress towards Millennium Development Goal 4. Lancet 2010;375:1988-2008.

27 Phillips JF, Macleod BB, Pence B. The household registration system: computer software for the rapid dissemination of demographic surveillance systems. Demogr Res 2000;2:40.

28 Picard R. GEODIST: Stata module to compute geodetic distances, 2019. Available: https://econpapers.repec.org/software/bocbocode/ s457147.htm [Accessed 20 Jul 2020].

29 Bloom DE, Freeman RB, Growth P. Labor Supply, and Employment in Developing Countries. Population Growth and Economic Development: Issues and evidence, 1987.

30 Karra M, Fink G, Canning D. Facility distance and child mortality: a multi-country study of health facility access, service utilization, and child health outcomes. Int J Epidemiol 2017;46:817-26.

31 McKinnon B, Harper S, Kaufman JS, et al. Distance to emergency obstetric services and early neonatal mortality in Ethiopia. Trop Med Int Health 2014;19:780-90.

32 Allotey P, Davey T, Reidpath DD. NCDs in low and middle-income countries - assessing the capacity of health systems to respond to population needs. BMC Public Health 2014;14 Suppl 2:S1. 
33 Tham TY, Tran TL, Prueksaritanond S, et al. Integrated health care systems in Asia: an urgent necessity. Clin Interv Aging 2018;13:2527-38.

34 Abdullah A, Hort K, Butu Y, et al. Risk factors associated with neonatal deaths: a matched case-control study in Indonesia. Glob Health Action 2016;9:30445.

35 GBD 2015 Mortality and Causes of Death Collaborators. Global, regional, and national life expectancy, all-cause mortality, and causespecific mortality for 249 causes of death, 1980-2015: a systematic analysis for the Global Burden of Disease Study 2015. Lancet 2016;388:1459-544.

36 Kinney MV, Kerber KJ, Black RE, et al. Sub-Saharan Africa's mothers, newborns, and children: where and why do they die? PLoS Med 2010;7:e1000294.

37 Oleribe OO, Momoh J, Uzochukwu BS, et al. Identifying key challenges facing healthcare systems in Africa and potentia solutions. Int J Gen Med 2019;12:395-403.

38 Kelly C, Hulme C, Farragher T, et al. Are differences in travel time or distance to healthcare for adults in global North countries associated with an impact on health outcomes? A systematic review. BMJ Open 2016:6:e013059.

39 Sarrassat S, Meda N, Badolo H, et al. Distance to care, care seeking and child mortality in rural Burkina Faso: findings from a population-based cross-sectional survey. Trop Med Int Health 2019;24:31-42.

40 Murielle GEA. La Discontinuité des Soins Prenatals en Côte d'Ivoire. IOSR-JEF 2019;10:37-47.

41 Moyer CA, Mustafa A. Drivers and deterrents of facility delivery in sub-Saharan Africa: a systematic review. Reprod Health 2013;10:40.

42 Sambo MN, Abdulrazaq GA, Shamang AF, et al. Household cost of antenatal care and delivery services in a rural community of Kaduna state, northwestern Nigeria. Niger Med J 2013;54:87-91.

43 Wigley AS, Tejedor-Garavito N, Alegana V, et al. Measuring the availability and geographical accessibility of maternal health services across sub-Saharan Africa. BMC Med 2020;18:237.

44 Okwaraji YB, Cousens S, Berhane Y, et al. Effect of geographical access to health facilities on child mortality in rural Ethiopia: a community based cross sectional study. PLoS One 2012;7:e33564. 